\title{
Simultaneous Determination of Potassium Sorbate and Sodium Benzoate in Doogh Using High Performance Liquid Chromatography
}

\author{
S. SOHRABVANDI ${ }^{1}$, H.VESAL ${ }^{2}$, A. M. MORTAZAVIAN ${ }^{1}$ and A.R. MOHAMMADI ${ }^{1}$ \\ 'Department of Food Science and Technology, Faculty of Nutrition Sciences, \\ Food science and Technology/National Nutrition and Food Technology Research Institute, \\ Shahid Beheshti University of Medical Sciences, Tehran, Iran. \\ 2Students' Research Committee, Department of Food Science and Technology, \\ International Branch of Shahid Beheshti University of Medical Sciences, Tehran, Iran. \\ ${ }^{*}$ Corresponding authors E-mail: mortazvn@sbmu.ac.ir / abdorreza@yahoo.com
}

http://dx.doi.org/10.13005/ojc/310362

(Received: April 02, 2015; Accepted: July 01, 2015)

\begin{abstract}
In this research, high performance liquid chromatography (HPLC) as a simple and rapid technique was used for the determination of potassium sorbate and sodium benzoate in different brands of Doogh (typical Iranian drink based on fermented milk). The chromatographic separation was achieved with a $\mathrm{C}_{18}$ column $(250 \mathrm{~mm} \times 4$ I.D, $5 \mu \mathrm{m})$ and one buffered mobile phase, acetate buffer $(0.2 \mathrm{~mol} / \mathrm{L}, \mathrm{pH} 4.4)$ : acetonitrile (63:37) at a flow rate of $1 \mathrm{~mL} / \mathrm{min}$. The effluent was monitored at $235 \mathrm{~nm}$, respectively. The main affecting factors, such as Carrez solution amount, $\mathrm{pH}$ and centrifuge speed were optimized. Limits of detection (LODs) were 1.823 for sorbic acid and 1.985 for benzoic acid. Relative standard deviations (RSDs) for quintuplicate analyses were 4.4 for sorbic acid and 4.087 for benzoic acid. The method also showed good linearity in a range from 4 to $1000 \mathrm{mg} / \mathrm{L}$ with correlation coefficients $\left(R^{2}\right)$ of 0.990 for sorbic acid and 0.995 for benzoic acid. Recoveries for the two analytes were 80 for sorbic acid and 65 for benzoic acid. Comparing to the other techniques, the proposed method was significantly less time-consuming and had more acceptable accuracy, precision and interruption elimination in samples. The developed method was successfully used for the routine monitoring of benzoate and sorbate in Doogh.
\end{abstract}

Key words: Doogh, High performance liquid chromatography, Potassium sorbate, Sodium benzoate.

\section{INTRODUCTION}

'Doogh' is a typical Iranian drink based on fermented milk which its dry matter is standardized by diluting of yogurt (after fermentation) or milk (before fermentation). It is considered as Iran national beverage. The annual production of Doogh was 800000 tons in 2012 with about 30000 tones export to other countries ${ }^{[1]}$. Milk solid non-fat content and fat content of Doogh are min. 3.2\% (W/W) and 
less than $50 \%$ of its total milk solid non-fat (MSNF), respectively. $\mathrm{pH}$ is max. 4.5 , while sodium chloride content ranges between $0.2-1.0 \%(\mathrm{~W} / \mathrm{W})^{2}$.

Food preservatives are added into foods to stop or delay spoilages as well as nutritional losses due to microbiological, enzymatic or chemical changes during their shelf life ${ }^{3}$. Sorbates (E200, E202-203) and benzoates (E210-213) are generally used in a great variety of foodstuffs including cheeses, confectionaries, sauces, and beverages and soft drinks. However, benzoic and sorbic acids could be harmful at higher than permitted safety levels. Some adverse effects, such as metabolic acidosis, convulsions, hyperpnoea, allergic reactions in experimental animals and in humans have been reported ${ }^{4}$. These preservatives are generally effective to control mold and inhibit yeast growth, and act against a wide range of bacterial attack ${ }^{5,6}$. Therefore, mentioned preservatives are permitted only in a limited dose in some foods according to National and International standards and their determination is a mandatory step in routine food analyses ${ }^{7}$. The permitted amounts of benzoic and sorbic acids including their sodium and potassium salts in fizzy drink are maximum 150 and 500 ppm, respectively8.

Up to now, methods such as gas chromatography $(\mathrm{GC})^{9-12}$ HPLC $^{13-20}$, thin layer chromatography (TLC) $)^{21,22}$ and capillary electrophoresis ${ }^{23-25}$ have been used to analyze benzoate and sorbate. High performance liquid chromatography (HPLC) is the most common analytical procedure for detecting and quantifying sorbic and benzoic acids in foods and beverages ${ }^{3,5}$. Several liquid chromatographic methods for the simultaneous determination of benzoic and sorbic acids have been reported ${ }^{3}$, however, no research has been done regarding measuring of mentioned preservatives in Doogh matrix, while some dairies in Iran might use them as adulteration. Therefore, the aim of this study was to develop a high performance liquid chromatography (HPLC) as a simple and rapid technique for determination of potassium sorbate and sodium benzoate in Doogh.

\section{MATERIALS AND METHODS}

\section{Materials}

Sodium benzoate and potassium sorbate were obtained from Dae Jung (South Korea). sulphuric acid, acetic acid and sodium chloride (analytical grade), sodium acetate, HPLC solvents, acetonitrile and water were obtained from Merck (Darmstadt, Germany). Sodium hydroxide was obtained from Acros (Belzhike). Carrez solution containing potassium hexaferrocyanide- $0.25 \mathrm{~mol} /$ $\mathrm{L}$ (Carrez solution I) and zinc acetate $-0.4 \mathrm{~mol} / \mathrm{L}$ (Carrez solution II) was purchased from Panreac (Belzhike).

Stock standard solutions of benzoate and sorbate were prepared together at a concentration of $1000 \mathrm{mg} / \mathrm{mL}$ in double-distilled water. To obtain a working solution $(100 \mathrm{mg} / \mathrm{mL})$, the upper standard solution was diluted with distilled water. The model solutions containing the required amount of each analyte $(4-1000 \mathrm{mg} / \mathrm{mL})$ were prepared by diluting stock and mixed standard solutions with doubledistilled water to evaluate the extraction performance under different conditions. Stock and working solutions were kept at $4^{\circ} \mathrm{C}$. All solvents were of analytical reagent grade or HPLC grade.

\section{Chromatographic analysis}

The chromatographic analysis was carried out with a Cecil CE-4100 and HPLC (Cambridge, England) equipped as follows: two CE-4100 pumps, multiple solvent delivery unit, vacuum degasser, mixing chamber, six-port valve (Rheodyne, USA), and CE-4200 UV-vis detector (Cambridge, England). An ODS column ( $250 \mathrm{~mm} \times 4$ I.D., $5 \mathrm{~mm}$ ) was used for these parathion of analytes. The injection volume was $20 \mathrm{~mL}$, and the column temperature was $25^{\circ} \mathrm{C}$ (ambient temperature). Separation of benzoate and sorbate was achieved using an acetate buffer $(0.2 \mathrm{~mol} / \mathrm{L}, \mathrm{pH} 3.6)$ : acetonitrile (63:37) acted as the mobile phase at a flow rate of $1 \mathrm{~mL} / \mathrm{min}$. The effluent was monitored at $235 \mathrm{~nm}$.

\section{Preparation of model sample}

To prepare the model sample, $104.7 \mathrm{~g}$ powdered milk and $20 \mathrm{~g} \mathrm{NaCl}$ were added to $2 \mathrm{~L}$ 
distilled water. After shaking, the closed vessel was placed in a water bath at $85^{\circ} \mathrm{C}$ for $30 \mathrm{~min}$; then, the temperature was decreased to $45^{\circ} \mathrm{C}$. Starter culture consisting of thermophilic yogurt culture $(\mathrm{CH} 1$ : ChrHansen, Horsholm, Denmark) was added to $1 \mathrm{~L}$ low-fat milk, and $10 \mathrm{~mL}$ of this mixture was added to the closed vessel at $45^{\circ} \mathrm{C}$; this was then placed in an incubator at $45^{\circ} \mathrm{C}$ for $6 \mathrm{~h}$. At this stage, the $\mathrm{pH}$ was modified to 4.2 , and the container was placed in a water bath at $15^{\circ} \mathrm{C}$. The prepared solution was refrigerated for 1 day. To optimize and calculate using the figure of merit, specified amounts of the mixed solution of benzoate and sorbate were spiked in the model sample.

\section{Preparation of test portion of Doogh for analysis}

$2 \mathrm{~mL}$ of spiked yogurt drink $(100 \mathrm{mg} / \mathrm{mL})$ was placed in a $15 \mathrm{~mL}$ screw cap, glass test tube. After adding $8 \mathrm{~mL}$ of $\mathrm{NaOH}(0.1 \mathrm{~mol} / \mathrm{L})$, the container was closed and shaken for $1 \mathrm{~min}$, then centrifuged and the upper phase was separated. In this step, $1.5 \mathrm{~mL} \mathrm{H} \mathrm{SO}_{4}(0.5 \mathrm{~mol} / \mathrm{L}), 1 \mathrm{~mL}$ potassium hexaferrocyanide (Carrez solution I) and $1 \mathrm{~mL}$ zinc acetate (Carrez solution II) were added to the precipitated protein phase, and the closed container was again shaken for $1 \mathrm{~min}$. After shaking, the closed container was centrifuged at $1389 \mathrm{~g}$ for 10 min. The aqueous phase was filtered and $10 \mathrm{~mL}$ was transferred to another conical flask, where the HPLC process was performed.

\section{RESULTS AND DISCUSSION}

The optimum separation and detection of potassium sorbate and sodium benzoate was achieved by the optimization of four variables which could affect the extraction yield in the HPLC procedure: Carrez solution amount, $\mathrm{pH}$, relative centrifugal force (RCF), and the volume of extracting solvent.

Effect of Carrez solution amount

$1 \mathrm{~mL}$ of Carrez solution caused complete sedimentation of proteins and increased the extraction efficiency to a maximum, which remains constant then (Fig. 1).

\section{Effect of $\mathrm{pH}$}

Extraction efficiency increased with increasing $\mathrm{pH}$ up to 12 . In alkaline $\mathrm{pHs}$, potassium sorbate and sodium benzoate change to ion form and their solubility in water increases but in acidic $\mathrm{pHs}$, molecular form of potassium sorbate and sodium benzoate is dominant and solubility of these compounds in the extraction solution is reduced; therefore, the efficiency of extraction would be slow (Fig. 2).

\section{Effect of extracting solvent volume}

Increase in extracting volume caused decrease of sodium benzoate and potassium sorbate concentration resulted in the reduction of the area under the peak and extraction efficiency. As a result, $6 \mathrm{~mL}$ extracting solvent would be proper and the lesser volumes are non-applicable (Fig. 3).

\section{Effect of relative centrifugal force (RCF)}

The increase of RCF to $1389 \mathrm{~g}$ resulted in the increase of extraction efficiency to a certain point and then (more than $1389 \mathrm{~g}$ ) remained almost constant (Fig. 4).

According to aforementioned results, the optimal values for the significant variables to obtain the maximum response could be determined.

\section{Quantitative analysis of benzoate and sorbate}

To evaluate the analytical performance of HPLC method, linearity, repeatability, recovery, limit of detection (LOD) and limit of quantification (LOQ) were investigated under optimal conditions. Calibration curves of benzoate and sorbate (standard solution) were linear over the range of 4$1000 \mathrm{mg} / \mathrm{mL}$. The curves were constructed by the peak area of benzoate and sorbate versus their concentrations for seven points (Fig. 5). The square

Table 1: Figures of merit for Doogh using the HPLC method

\begin{tabular}{lcccccc}
\hline Analyte & Linear Range & $\mathbf{R}^{\mathbf{2}}$ & Recovery & LOD & LOQ & RSD \\
\hline Sodium benzoate & $4-1000$ & 0.995 & 65 & 1.985 & 6.619 & 4.087 \\
Potassium sorbate & $4-1000$ & 0.990 & 80 & 1.823 & 6.078 & 4.4 \\
\hline
\end{tabular}




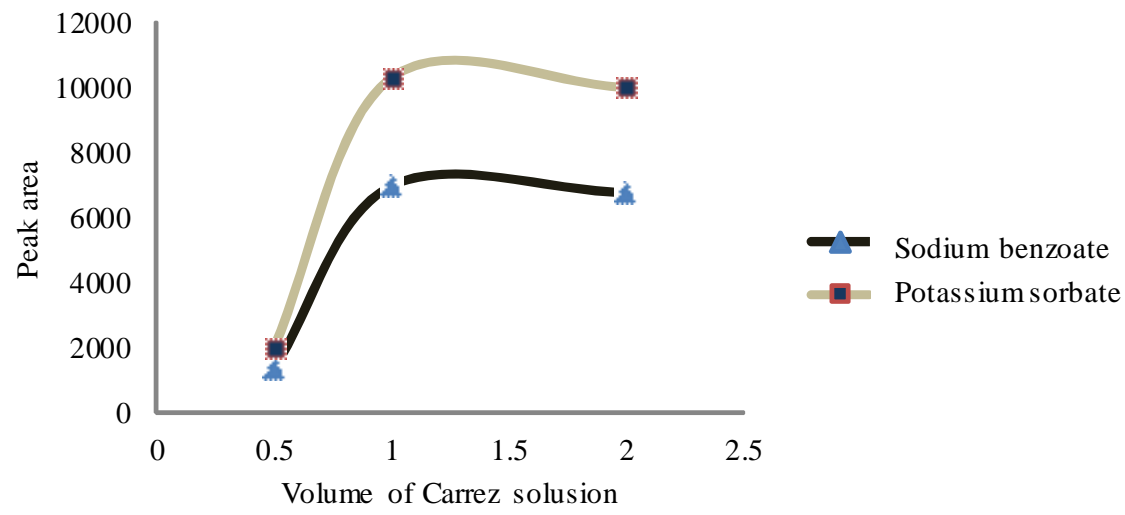

Fig. 1: Effect of Carrez solution volume on sodium benzoate and potassium sorbate extraction efficiency

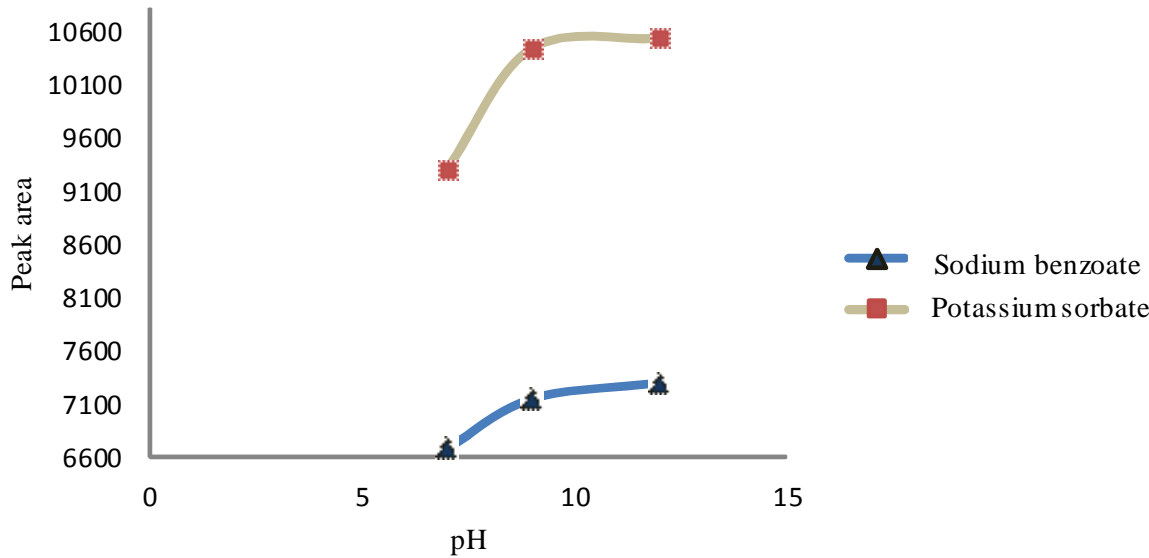

Fig. 2. Effect of relative centrifugal force (RCF) on sodium benzoate and potassium sorbate extraction efficiency

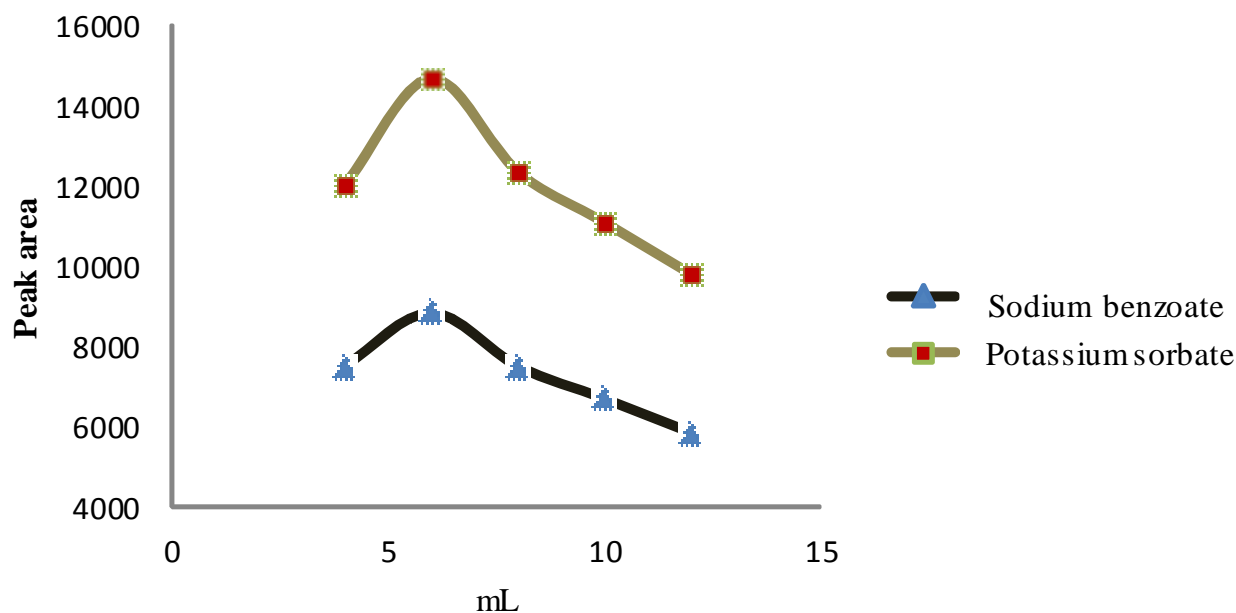

Fig. 3: Effect of extracting solvent volume on sodium benzoate and potassium sorbate extraction efficiency 


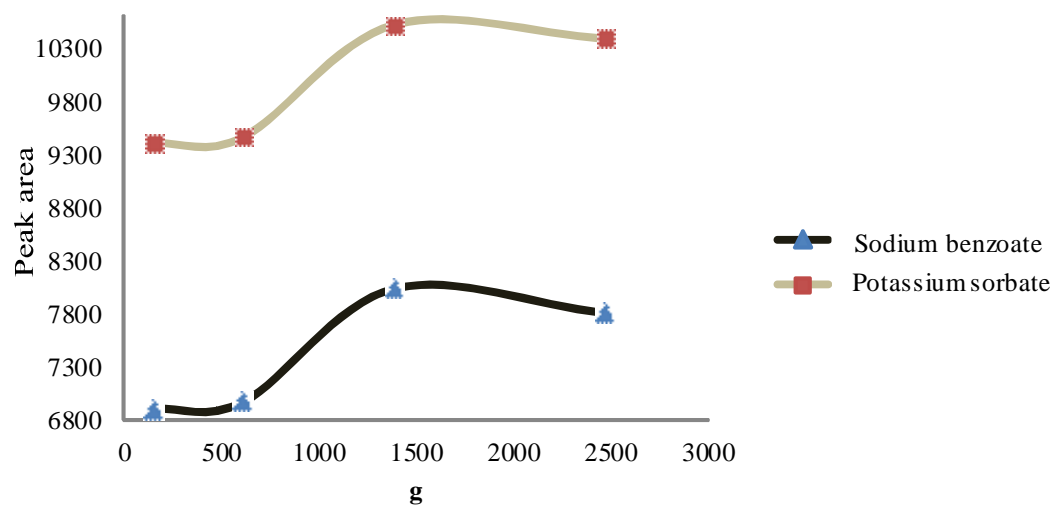

Fig. 4: Effect of pH on sodium benzoate and potassium sorbate extraction efficiency
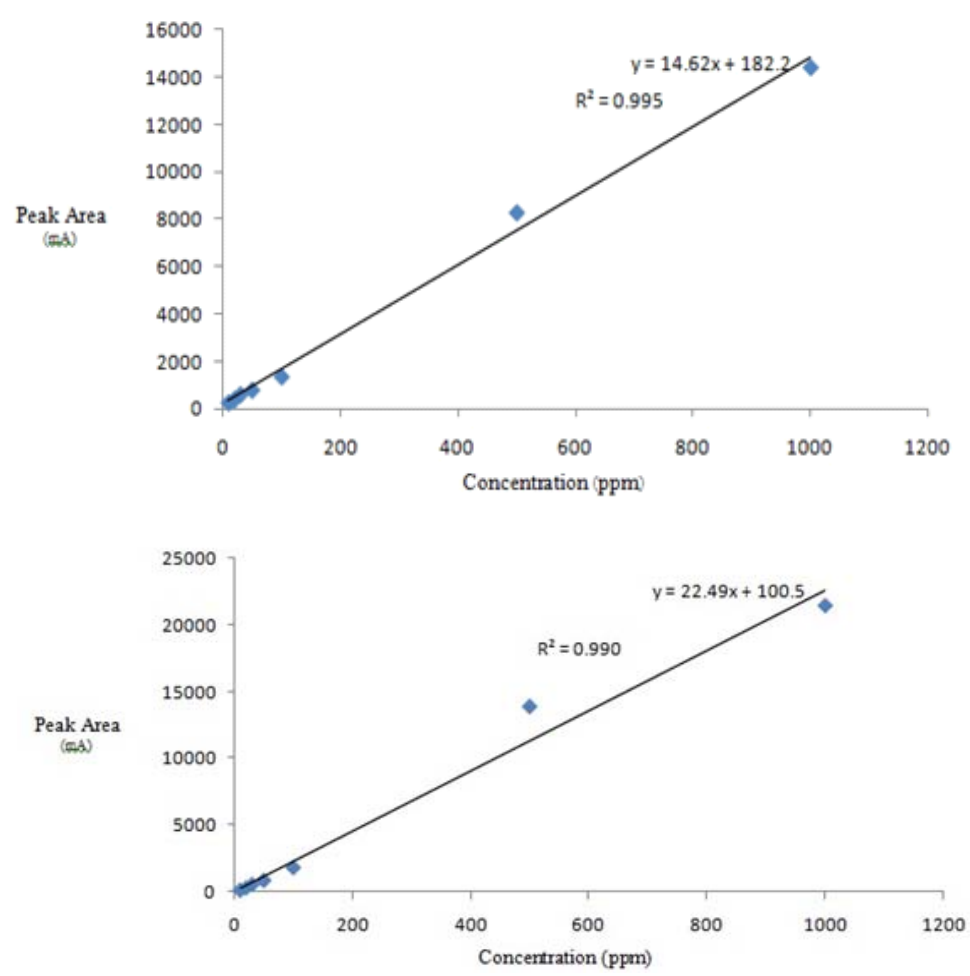

Fig. 5: Calibration curves for sodium benzoate (A) and potassium sorbate (B)

of the correlation coefficient $\left(R^{2}\right)$ were 0.995 and 0.990 for benzoate and sorbate, respectively. Relative standard deviation (RSD) was $4.4 \%$ for sorbate and $4.087 \%$ for benzoate. The detection limit of proposed method for potassium sorbate and sodium benzoate were $1.823 \mathrm{mg} / \mathrm{L}$ and $1.985 \mathrm{mg} /$ $\mathrm{L}$, respectively. Also, the LOQs achieved were 6.078 $\mathrm{mg} / \mathrm{L}$ for potassium sorbate and $6.619 \mathrm{mg} / \mathrm{L}$ for sodium benzoate (Table 1). The chromatogram obtained by HPLC for Doogh under optimum conditions with $0.1 \mathrm{mg} / \mathrm{mL}$ of benzoate and sorbate (Fig. 5).

\section{CONCLUSION}

Since the valid method for monitoring the potassium sorbate and sodium benzoate extraction in Doogh had been not carried out previously, validation and optimization of the test method to measure mentioned preservatives was far important and urgently required. In this work, the factors 
affecting the Potassium sorbate and sodium benzoate extraction from Doogh $(\mathrm{pH}$ of the sample, the extracting solvent volume, amount of Carrez solution and RCF) were optimized. The HPLC system allowed an efficient analysis with a considerable gain in the speed of chromatographic analysis; because HPLC has minimal preparation requirement, does not require derivatization, and provides short extraction time, good precision and no matrix interference. The developed method could be successfully used for the routine monitoring of benzoate and sorbate in Doogh in regulatory centers and factories.

\section{ACKNOWLEDGMENTS}

This study has been supported by the National Nutrition \& Food Technology Research Institute of Iran. We gratefully acknowledge its assistance.

\section{REFERENCES}

1. Anon. Doogh: Specifications and test methods. Available at http://www.isiri.org. Accessed December 10, 2013. No. 2453.

2. Codex alimentarius commission CX/NEA 09/ 5/8. Fifth Session; Project document for a regional standard for Doogh. 2009.

3. Ferreira, I.; Mendes, E.; Brito, P.; Ferreira, M. A. Simultaneous determination of benzoic and sorbic acids in quince jam by HPLC. Food Res. Int. 2000, 33(2), 113-117.

4. Lino, C. M.; Pena, A. Occurrence of caffeine, saccharin, benzoic acid and sorbic acid in soft drinks and nectars in Portugal and subsequent exposure assessment. Food Chem. 2010, 121(2), 503-508.

5. Khosrokhavar, R.; Sadeghzadeh, N.; Amini, N.; Ghazi-Khansari, M.; Hajiaghaee, R.; Mehr Sh. Simultaneous determination of preservatives (sodium benzoate and potassium sorbate) in soft drinks and herbal extracts using high-performance liquid chromatography (HPLC). J. Med. Plants 2010, 9(35), 80-87.

6. Dong, C.; Mei, Y.; Chen, L. Simultaneous determination of sorbic and benzoic acids in food dressing by headspace solid-phase microextraction and gas chromatography. J. Chromatogr. A 2006, 1117(1), 109-114.

7. Pylypiw, H. M.; Grether, M. T. Rapid highperformance liquid chromatography method for the analysis of sodium benzoate and potassium sorbate in foods. J. Chromatogr. $A$ 2000, 883(1-2), 299-304.

8. Jungel, P.; de Koning, S.; Brinkman, U. A. T.; Melcher, E. Analyses of the wood preservative component $\mathrm{N}$-cyclohexyldiazeniumdioxide in impregnated pine sapwood by direct thermal desorption-gas chromatography-mass spectrometry. J. Chromatogr. A 2002, 953, 199-205.

9. Archer, A. W. Determination of benzoic and sorbic acids in orange juice by highperformance liquid chromatography. Analyst 1980, 407-409.

10. Wang, L.; Zhang, X.; Wang, Y.; Wang, W. Simultaneous determination of preservatives in soft drinks, yogurts and sauces by a novel solid-phase extraction element and thermal desorption-gas chromatography. Anal. Chim. Acta 2006, 577, 62-67.

11. Shanmugam, G.; Ramaswamy, B. R.; Radhakrishnan, V.; Tao, H. GC-MS method for the determination of paraben preservatives in the human breast cancerous tissue. Microchem. J. 2010, 96, 391-396.

12. Mroueh, M. D.; Issa, D.; Khawand, J.; Haraty, B.; Malek, A.; Kassaify, Z.; Toufeili, I. Levels of benzoic and sorbic acid preservatives in commercially produced yoghurt in Lebanon. J. Food Agr. Environ. 2008, 6, 62-66.

13. Omar, M. N.; Hazwani, M. H. N.; Nazreen, M. N. M.; Zuberdi, A. M. Studies on Frying Quality of Virgin Coconut Oil and Shortening Blends. Orient J. Chem. 2014, 30(3), 1279-1286.

14. Costa, A. C. O.; Perfeito, L. S.; Tavares, M. F. M.; Micke, G. A. Determination of sorbate and benzoate in beverage samples by capillary electrophoresis-Optimization of the method with inspection of ionic mobilities. J. Chromatogr. A 2008, 1204, 123-127. 
15. Ling, D. S.; Xie, H.Y.; He, Y.Z.; Gan, W. E.; Gao, $Y$. Determination of preservatives by integrative coupling method of headspace liquid-phase microextraction and capillary zone electrophoresis. J. Chromatogr. A2010, 1217, 7807-7811.

16. Ramaswamy, B. R.; Kim, J. W.; Isobe, T.; Chang, K. H.; Isobe, T.; Tanabe, S. Determination of preservative and antimicrobial compounds in fish from Manila Bay, Philippines using ultra high performance liquid chromatography tandem mass spectrometry, and assessment of human dietary exposure. J. Hazard. Mater. 2011, 192, 1739-1745.

17. Lozano, V. A.; Camina, J. M.; Boeris, M. S. Simultaneous determination of sorbic and benzoic acids in commercial juices using the PLS-2 multivariate calibration method and validation by high performance liquid chromatography. Talanta 2007, 73, 282-286.

18. Lino, C., Pena, A. Occurrence of caffeine, saccharin, benzoic acid and sorbic acid in soft drinks and nectars in Portugal and subsequent exposure assessment. Food Chem. 2010, 121, 503-508.

19. Wei, R.; Li, W.; Yang, L.; Jiang, Y.; Xie, T. Online preconcentration in capillary electrophoresis with contactless conductivity detection for sensitive determination of sorbic and benzoic acids in soy sauce.
Talanta 2011, 83, 1487-1490.

20. Saad, B.; Bari, F.; Saleh, M. I.; Ahmad, K.; Talib, M. Simultaneous determination of preservatives (benzoic acid, sorbic acid, methylparaben and propylparaben) in foodstuffs using high-performance liquid chromatography. J. Chromatogr. A 2005 , 1073, 393-397.

21. Thomassin, M.; Cavalli, E.; Guillaume, Y.; Guinchard, C. Comparison of quantitative high performance thin layer chromatography and the high performance liquid chromatography of parabens. J. Pharm. Biomed. 1997, 15, 831-838.

22. Campos, C.; Gerschenson, L. I. A. N.; Alzamora, S. M. Analysis of nine food additives in red wine by ion-suppression. J. Food. Sci. 1991, 56, 863-871.

23. Tang, Y.; Wu, A. M. Quick method for the simultaneous determination of ascorbic acid and sorbic acid in fruit juices by capillary zone electrophoresis. Talanta 2005, 65(3), 794-798.

24. Tfouni, S. A. V.; Toledo, M. C. F. Determination of benzoic and sorbic acids in Brazilian food. Food Control 2002, 13(2), 117-3.

25. Ahmadi, A.; Ziarati, P. Chemical Composition Profile of Canned and Frozen Sweet Corn (Zea mays L.) in Iran. Orient J. Chem. 2015, 31(2), 1065-1070. 